\title{
Liposarcoma Arising in a Giant Lipomatous Polyp of the Esophagus
}

\author{
Young-Tae Bak, M.D., Jin Ho Kim, M.D., Jong Guk Kim, M.D. and Chang Hong Lee, M.D. \\ Department of Internal Medicine, Korea University College of Medicine, Seoul, Korea
}

Kap No Lee, M.D.

Department of Clinical Pathology

Young Ho Choi, M.D. and Hark Jei Kim, M.D.

Department of Thoracic and Cardiovascular Surgery

\begin{abstract}
A case of liposarcoma in a giant pedunculated lipoma of the esophagus in a 49-year-old Korean woman who presented intermittent swallowing difficulty for 3 years is reported. Endoscopy and esophagography revealed that a giant smooth longitudinal tumor mass almost entirely occupied the esophageal lumen. A total esohagectomy was done. The tumor was $20 \mathrm{~cm}$ in length and $7 \mathrm{~cm}$ in average diameter with an obvious stalk measuring $3 \mathrm{~cm}$ in length and $1 \mathrm{~cm}$ in diameter. Microscopic examination disclosed a lipoma with focal ulceration and liposarcomatous change infiltrating into interstitial fibrous tissue at its distal end.
\end{abstract}

Key Words: Liposarcoma, Esophagus, Lipomatous Polyp, Pedunculated lipoma

\section{INTRODUCTION}

Benign pedunculated esophageal tumors are rare ${ }^{1-12)}$ and pedunculated malignant esophageal tumors are extremely rare ${ }^{3.6)}$. Only one case report of pedunculated esophageal liposarcoma was found in the literature. ${ }^{14)}$ We report the first case of a lipomatous polyp with liposarcomatous change.

\section{CASE REPORT}

A 49-year-old Korean woman presented intermittent swallowing difficulty, especially when eating solid foods, for the duration of 3 years. The symptom had been aggravated for the last 5 months. Anorexia, nausea and weight loss developed in the 3 months before admission. Other complaints were palpitation and chest discomfort for a year before

Adress reprint requests: Young-Tae Bak. MD, Department of internal Medicine. Guro Hospital, Korea University College of Medicine, 80 Guro-dong. Guro-gu, Seoul 152-050. Korea admission.

Physical examination revealed that the vital signs were stable except the body temperature which was $38.8^{\circ} \mathrm{C}$. She appeared slightly pale. Neck veins and superficial veins of the upper anterior chest wall were slightly engorged. The patient appeared unremarkable otherwise.

Laboratory data revealed microcytic and hypochromic anemia with hemoglobin of $86 \mathrm{~g} / \mathrm{L}$. The white blood cell count was $12.3 \times 10 / \mathrm{L}$. Serum protein was $55 \mathrm{~g} / \mathrm{L}$ and albumin was $24 \mathrm{~g} / \mathrm{L}$. Other chemistry results, including thyroid function test, were within normal range. The urinalysis, serum antimicrosomal antibody and antithyroglobulin antibody were within normal limits.

The chest $x$-ray showed mediastinal widening with an air shadow within it. Esophagography revealed massive dilatation of the esophagus with a huge sausage-shaped filling defect along almost the entire length of the esophagus (Fig. 1). On esophagoscopy, a huge smooth elongated mass, filling almost the entire lumen of the esophagus, was found. The tumor appeared to be covered by smooth 


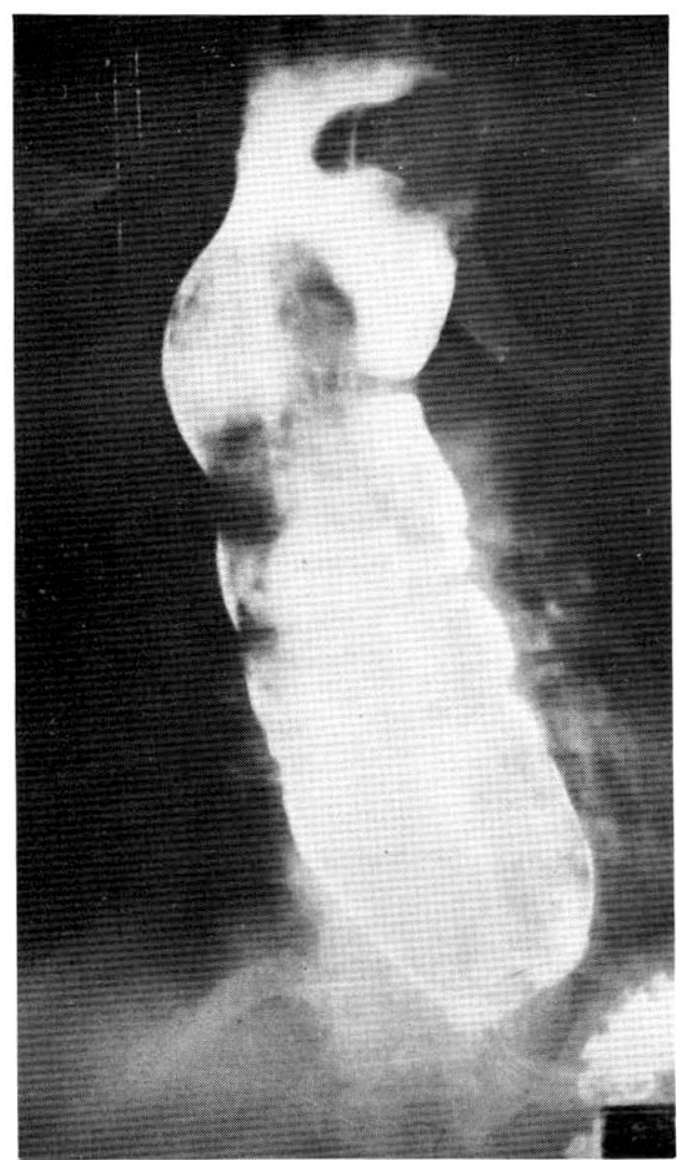

Fig. 1. Barium esophagogram shows the massively dilated esophagus with a huge sausage-shaped filling defect along almost the entire length of the esophagus.

mucosa resembling the normal esophageal mucosa. The proximal end of the mass was lobulated and there was bluish discoloration at its distal end. The tumor was too large to be removed by an endoscopic procedure. The computerized tomogram of the chest demonstrated a huge esophageal intraluminal mass. Fatty component was suggested to be the main constituent of its upper portion (Fig. 2).

A total esophagectomy and esophago-cologastrostomy were performed. The mass was $20 \mathrm{~cm}$ in length, $7 \mathrm{~cm}$ in diameter and had a stalk measuring $3 \mathrm{~cm}$ in length and $1 \mathrm{~cm}$ in diameter just below the pharyngoesophageal junction (Fig. 3). The proximal end of the mass was lobulated. It was mostly covered by grossly unremarkable smooth mucosa with ulceration and necrosis at the distal end. The

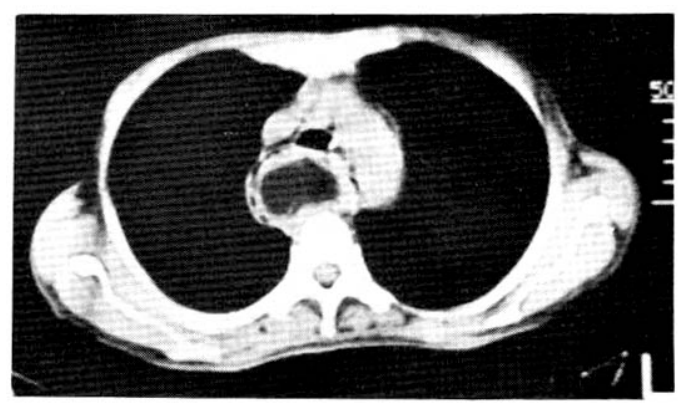

Fig. 2. Computerized tomogram of the chest demonstrates a huge intraluminal low density mass in the esophagus.

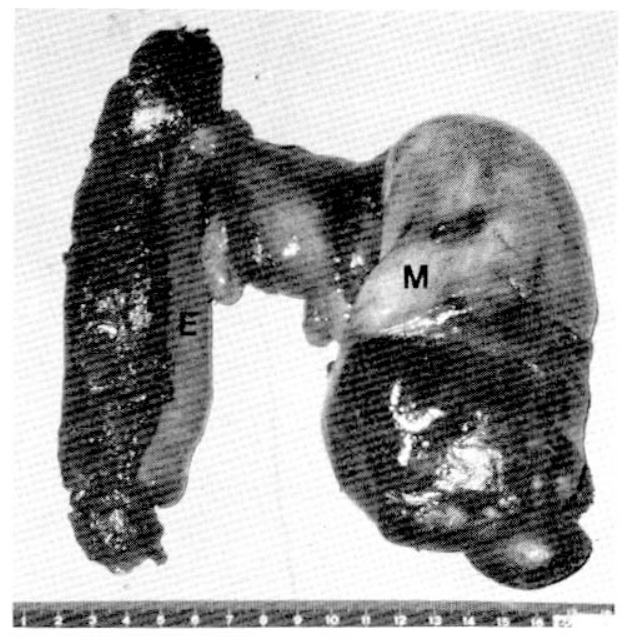

Fig. 3. Total esophagectomy specimen shows a pedunculated mass of $20 \mathrm{~cm}$ in length and $7 \mathrm{~cm}$ in diameter with a stalk $3 \mathrm{~cm}$ in length and $1 \mathrm{~cm}$ in diameter ( $E$ : esophagus; $M$ : mass).

pathological examination disclosed lipoma with sarcomatous change at the distal end with interstitial infiltration of the well differentiated liposarcoma cells into the adjacent lipomatous area (Fig. 4).

There was no evidence of invasion at the stalk or metastasis to other sites. Except for a leakage from the proximal anastomosis site, which required another operation on the 8th postoperative day, the patient recovered and was discharged from the hospital. She remained well and was on a regular diet for the following 7 months until now.

\section{DISCUSSION}

Benign tumors of the esophagus usually arise 


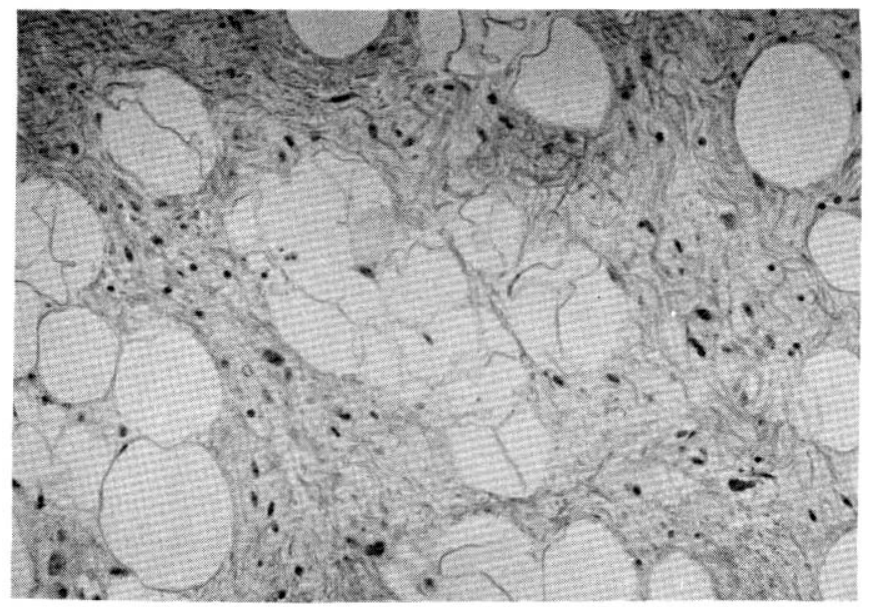

Fig. 4. Microscopic finding shows well differentiated liposarcoma (H\&E, x200).

from the lower portion of the esophagus. But the pedunculated tumors commonly arise from the upper fourth of the esophagus. ${ }^{3-5)}$ The wall of the upper portion of the esophagus is thinner and is habitually approximated by tonic muscular contractions. The peristaltic action of the esophagus tends to elongate and mold the tumor and gives rise to a pedicle. ${ }^{3.4)}$ These intraluminal pedunculated tumors are largely mesenchymal in origin. The reported cases were lipomas, pedunculated lipomas, fibrolipomas, fibrovascular polyps, and combinations of these terms. "')

Squamous cell carcinoma, adenocarcinoma and leiomyosarcoma were also reported in the pedunculated tumors of the esophagus. But it has not been proved whether they are malignant tranformations from benign tumors or malignacy de novo.3.6.13)

Primary liposarcomas may arise wherever adipose tissue is present. The esophageal wall does have a small amount of adipose tissue. As expected, there are several reports of esophageal lipomas ${ }^{1.2 .4 .6-8)}$ and only one report of liposarcoma of the esophagus. ${ }^{(4)}$ However, there has been no report of liposarcoma arising in the lipomatous polyp. This is the first case to be reported.

The symptoms of the pedunculated tumors are sometimes so minimal that leads to a delay in the diagnosis until they became large enough to produce serious symptoms. The symptoms of all neoplasms of the esophagus are practically the same and one cannot make a diagnosis from the symptoms. Neoplasms, when large enough, may produce stenosis with severe dysphagia, regurgitation of food and marked dilatation of the esophagus. A pedun- culated tumor itself may be regurgitated into the oral cavity or into the larynx causing cough, hoarseness, dyspnea or even death. 1-4, 7-12)

In the esophagogram, the dilatation of the esophagus can incorrectly suggest achalasia if the tumor itself is overlooked. Even endoscopy can miss the tumor, and a biopsy may miss the exact nature of the tumor as it is covered with normal epithelium. ${ }^{12)}$

Once the pedunculated tumor of the esophagus is diagnosed, resection is indicated because of progressive dysphagia, possible fatal regurgitation, possible bleeding and possible chance of malignancy. Surgical removal through cervical esophagotomy for the larger tumors or endoscopic removal for the smaller ones is usually known to be sufficient. But because of the frequent presence of large vessels in the stalk, the direct surgical approach is more prudent and is the treatment of choice for most pedunculated esophageal polyps except for smaller ones. ${ }^{9-12)}$ There is frequent local recurrence of liposarcomas of other organs ${ }^{14}$ and meticulous followup should be done.

\section{REFERENCES}

1. Vinson PP: A pedunculated lipoma of the esophagus. J A M 78:801, 1922

2. Garretson WT, Hardie GC: Another case of pedun-. culated lipoma of the esophagus. J A M A 90:1373, 1928

3. Samson PC, Zelman J: Pedunculated tumors of the esophagus. Arch Otolaryngol 36:203, 1942 
4. Moersch HJ, Harrington SW: Benign tumor of the esophagus. Ann Otol Rhinol Laryngol 53:800, 1944

5. Beeler RC, Collins JN, Hall MF: Benign pedunculated tumors of the esophagus. Am J Roentgenol 60:466. 1948

6. Marcial-Rojas RA, Suau P: Epidermoid carcinoma in mucosa overlying a pedunculated lipoma of the esophagus. I Thorac Surg 37:427, 1959

7. Nora PF: Lipoma of the esophagus. Am J Surg 108:353, 1964

8. Allen MS, Talbot WH: Sudden death due to regurgitation of a pedunculated esophageal lipoma. J Thorac Cardiovasc Surg 54: 756, 1967

9. Patel J, Kieffer RW, Martin M, Avant GR: Giant fibrovascular polyp of the esophagus. Gastroenterology 87:953, 1984
10. Alberti-Flor JJ, Dunn GD, Karl M, Halter S, Krueger TC: Large hypopharyngeal polyp producing intermittent dysphagia and acute airway obstruction. Am J Gastroenterol 81:721, 1986

11. Cole FH. Hays A, Tucker C: Giant esophageal fibrolipoma. J Tenn Med Assoc 80:267, 1987

12. van Lanchot JJB, Poublon RML, Zonderland HM, van Houten $\mathrm{H}$ : Benign pedunculated tumor of the esophagus. Neth J Surg 39:83, 1987

13. Vinson PP, Kennedy FS: The association of benign and malignant lesions of the esophagus. Am J Med Sci 186.660, 1933

14. Mansour KA, Fritz RC, Jacobs DM, Vellios F: Pedunculated liposarcoma of the esophagus: a first case report. J Thor Cardiovasc Surg 86:447, 1983 